\title{
Elucidating the Trajectory of the Charge Transfer Mechanism and Recombination Process of Hybrid Perovskite Solar Cells
}

\author{
Joseph K. Kirui ${ }^{1} \oplus$, Solomon Akin Olaleru ${ }^{1,2,3,4, *}$, Lordwell Jhamba ${ }^{1}$, Daniel Wamwangi ${ }^{5}$, Kittessa Roro ${ }^{2}$, \\ Adam Shnier ${ }^{5}$ (D) Rudolph Erasmus ${ }^{5}$ and Bonex Mwakikunga ${ }^{3,6}$ \\ 1 Physics Department, University of Venda, Thohoyandou 0950, South Africa; \\ joseph.kirui@univen.ac.za (J.K.K.); lordwell.jhamba@univen.ac.za (L.J.) \\ 2 CSIR-Energy Centre, Council for Scientific and Industrial Research, P.O. Box 395, Pretoria 0001, South Africa; \\ kroro@csir.co.za \\ 3 DST/CSIR-National Centre for Nano-Structured Materials, P.O. Box 395, Pretoria 0001, South Africa; \\ bmwakikunga@csir.co.za \\ 4 Physics Department, Yaba College of Technology, P.M.B 2011, Lagos 100001, Nigeria \\ 5 School of Chemistry and DSI-NRF Centre of Excellence in Strong Materials (CoE-SM), University of \\ Witwatersrand, Johannesburg 2050, South Africa; Daniel.Wamwangi@wits.ac.za (D.W.); \\ adamshnier@gmail.com (A.S.); Rudolph.Erasmus@wits.ac.za (R.E.) \\ 6 Physics Department, Arcadia Campus, Tshwane University of Technology, P.O. Box 680, \\ Pretoria 0001, South Africa \\ * Correspondence: akinolaleru@gmail.com; Tel.: +27-783-901-714
}

check for

updates

Citation: Kirui, J.K.; Olaleru, S.A.; Jhamba, L.; Wamwangi, D.; Roro, K.; Shnier, A.; Erasmus, R.; Mwakikunga, B. Elucidating the Trajectory of the Charge Transfer Mechanism and Recombination Process of Hybrid Perovskite Solar Cells. Materials 2021, 14, 2698. https://doi.org/10.3390/ ma14112698

Academic Editor: Makoto Karakawa

Received: 3 April 2021

Accepted: 14 May 2021

Published: 21 May 2021

Publisher's Note: MDPI stays neutral with regard to jurisdictional claims in published maps and institutional affiliations.

Copyright: (c) 2021 by the authors. Licensee MDPI, Basel, Switzerland. This article is an open access article distributed under the terms and conditions of the Creative Commons Attribution (CC BY) license (https:// creativecommons.org/licenses/by/ $4.0 /)$.

\begin{abstract}
Perovskite-based solar cells (PSCs) have attracted attraction in the photovoltaic community since their inception in 2009. To optimize the performance of hybrid perovskite cells, a primary and crucial strategy is to unravel the dominant charge transport mechanisms and interfacial properties of the contact materials. This study focused on the charge transfer process and interfacial recombination within the $n-i-p$ architecture of solar cell devices. The motivation for this paper was to investigate the impacts of recombination mechanisms that exist within the interface in order to quantify their effects on the cell performance and stability. To achieve our objectives, we firstly provided a rationale for the photoluminescence and UV-Vis measurements on perovskite thin film to allow for disentangling of different recombination pathways. Secondly, we used the ideality factor and impedance spectroscopy measurements to investigate the recombination mechanisms in the device. Our findings suggest that charge loss in PSCs is dependent mainly on the configuration of the cells and layer morphology, and hardly on the material preparation of the perovskite itself. This was deduced from individual analyses of the perovskite film and device, which suggest that major recombination most likely occur at the interface.
\end{abstract}

Keywords: interface; recombination; ideality factor; perovskite solar cell

\section{Introduction}

Hybrid perovskites are currently regarded as inspiring novel materials for basic studies and practical applications in optoelectronic devices because of their unusual and useful properties emerging from their mix of organic and inorganic constituents [1]. The perovskites are direct bandgap semiconducting materials with strong absorption edges and high luminescence efficiency and without a Stokes shift. Furthermore, perovskites demonstrate exceptional optoelectronic properties, such as effective photon recycling, high free-carrier diffusion, and an ambipolar nature to the transfer of electrons and holes [2-4]. These intrinsic physical properties are among the main parameters responsible for the high PCE values in PSCs, and are also the reason why perovskite materials can function in various configurations. Regardless of the fact that the present record for the highest PCE value in PSCs is $25.2 \%$ [5], a profound knowledge of the processes regarding charge transport and recombination among layers and within the perovskite layer is a primary 
necessity for more improvements [3]. Additionally, the interfaces between the perovskite film and the contact layers are the main determinants for the PCE and have little impact on the stability of HPSCs [5].

Thin-film perovskite solar cells have a sandwich architecture; during the photovoltaic process, the incident photons generate electrons and holes when they are absorbed by the perovskite material. These free carriers move within the perovskite to the interface of individual charge specific contacts, and thereafter are collected in electrodes. In a simplified way, electrons should be moved from the absorber film to electrodes without losses. Subject to the deposition strategies [3,6] and the composite of the perovskite [7] being employed, energetic disorder can occur in the crystal boundaries, which serve as recombination points for losses. As a means to limit these recombination locations, tremendous attempts have been made to enhance the properties of the perovskite materials during compositional engineering [7], interface modification [8], or processing techniques such the gas-phase method [9]. Nevertheless, interfaces are susceptible to losses owing to energy level misalignment, poor contacts, or defects at interface, which result in high charge accumulation, leading to a decline in the efficiency of the solar cell, particularly in open-circuit state $[10,11]$. Specifically, it remains unclear how the observed alterations directly affect the transfer of charge carriers throughout the interface.

Due to the multilayered structure of perovskite solar cells, interfaces in the heterostructure play a key role in the separation of charges and also influence the long-term stability of the device. Hence, it is necessary to design and regulate the charge extraction throughout the contacts so as to limit the loss of energy, increase the quality of the device, and also strengthen the stability. The presence of different contact materials complicates the formation of ohmic contacts as a result of differences in bandgaps between materials, which results in a Schottky interface.

Radiative recombination of charge carriers appears not to contribute significantly compared to the nonradiative recombination process in the PSCs $[12,13]$. The nonradiative recombination occurs when the trapped charge carrier, which is positioned at the energy level across the bandgap, recombines with a carrier of opposite charge. However, the traps may be basically built-up either at the grain boundaries of the perovskite material [14] or at the interfaces between the perovskite and contact layers [15]. It appears that the two kinds of accumulation occur in the PSCs and affect the overall performance [12,13]. Overall, it has been generally established that interface recombination does influence the properties of the solar cells $[12,16]$. However, for PSCs, only recently have studies been published on the significance of this kind of recombination [12,17-19].

With the aim of unlocking the potential of PCEs for single-junction and tandem perovskite solar cells, it is vital to advance the knowledge of the underlying recombination loss mechanisms. It has been clearly established that nonradiative recombination losses are the key factors holding back the PSCs from reaching their full thermodynamic potential $[20,21]$. Nonradiative recombination losses reduce both the open-circuit voltage $\left(V_{\mathrm{oc}}\right)$ of the device and the fill factor due to the ideality factor being greater than one [20,22].

The origin of nonradiative recombination losses in PSCs continues to be an intensely discussed subject. Initially, a concerted effort was focused on limiting trap-assisted recombination at defects in the perovskite bulk or at grain boundaries $[20,23,24]$. Indeed, appreciable enhancements have been accomplished, resulting from the improvements in the fabrication and design of perovskite to enhance the grain size and improve the crystallinity and material optimization. However, issues regarding the interfacial properties of contact materials and their many impacts on the performance and stability of such devices need to be resolved to allow full commercialization of PSCs.

Most of the previous studies on the electrical characterization of perovskite solar cells focused on mesoporous structured cells $[25,26]$. Because of the similarity in the mesoporous perovskite device structure with that of dye-sensitized solar cells (DSSCs), early perovskite studies sought to interpret the device response in a similar manner. The studies centered around the challenges in resolving the impacts of the mesoporous layer from the intrinsic 
behavior of the perovskite active layer. The primary reason behind the emphasis on mesoporous cells was that it appeared to be easier to make high-performance cells with good steady-state properties (such as low hysteresis), utilizing the mesoporous as opposed to the planar heterojunction structure [27]. However, to investigate the electronic properties of the perovskite layer itself effectively, it is advisable to study planar heterojunction devices [10]. In this type of FTO-ZnO-perovskite-Spiro-OMeTAD-Au device, the flat perovskite layer is in contact with two different carrier transport materials, thus making it easier to examine the intrinsic behavior. In addition, all of the materials used in this device are dopant-free. Our aim here is two-fold: firstly, to investigate the charge transfer process without the added complexity of dopant materials, and secondly to assess the impacts of recombination mechanisms that exist within the interface, together with the effects on the stability of the device.

To the best of our knowledge, apart from previous articles on devices based on the mesoporous architecture $[25,26]$, no studies of the planar architecture of dopant-free PSCs have been reported so far. The focus of this paper is on the studies of the basic photovoltaic parameters of PSCs and their optoelectronic properties. In the first part, we account for the photoluminescence and UV-Vis measurements on perovskite thin film to elucidate different recombination pathways. In the second part, we use ideality factor measurements (I-V curve) and impedance spectroscopy to establish the recombination mechanisms in the device.

\section{Materials and Methods}

Our hybrid perovskite was made from organic and inorganic sources using a solutionprocessed method. The organic source was methylammonium iodide $\left(\mathrm{CH}_{3} \mathrm{NH}_{3} \mathrm{I}\right)$ and the inorganic source is lead iodide $\left(\mathrm{PbI}_{2}\right)$. Most of the materials used as shown in Table 1 were purchased from Sigma Aldrich.

Table 1. Material used for different layers in fabricated perovskite solar cells.

\begin{tabular}{cc}
\hline Layer & Material \\
\hline Cathode & Fluorine tin oxide $(\mathrm{FTO})$ \\
Electron transport layer (ETL) & Zinc oxide $(\mathrm{ZnO})$ \\
Active layer & Perovskite $\left(\mathrm{CH}_{3} \mathrm{NH}_{3} \mathrm{PbI}_{3}\right)$ \\
Hole transport layer (HTL) & Spiro-OMeTAD \\
Anode & Gold $(\mathrm{Au})$ \\
\hline
\end{tabular}

\subsection{Fabrication of Perouskite Solar Cell}

Devices were manufactured on fluorine-doped tin oxide (FTO) coated on glass substrates, as shown in Figure 1. The FTO layer was etched using zinc powder and diluted hydrochloric acid (2M HCL) mixture to enable fabrication of top electrode contact pads without shorting of the devices. The glass substrates were rinsed with water. All etched substrates were cleaned with deionized water and acetone via sonication for about $30 \mathrm{~min}$ before rinsing with ethanol and deionized water. Substrates were then dried with $\mathrm{N}_{2}$ gas. On this partially etched substrate, zinc oxide was deposited by radio frequency (RF) magnetron sputtering over a $\mathrm{ZnO}$ target. The etched FTO-coated substrate was mounted on the rotating stage inside the sputtering chamber and the working gas pressure was kept at $10 \mathrm{mTorr}$ during the sputtering process. High-energy Ar ions bombarded the $\mathrm{ZnO}$ target, thereby lifting the target molecules that were deposited onto the FTO-coated glass substrate and creating the $\mathrm{ZnO}$ film. The preparation of precursor solutions and spin-coating were carried out under normal room temperature conditions with the presence of oxygen and moisture.

Light absorbing perovskite was deposited on top of the $\mathrm{ZnO}$ layer using a single coating procedure accompanied by immediate annealing. Methylamine iodide $\left(\mathrm{CH}_{3} \mathrm{NH}_{3} \mathrm{I}\right)$ $(0.160 \mathrm{~g})$ and lead iodide $\left(\mathrm{PbI}_{2}\right)(0.460 \mathrm{~g})$ were dissolved in dimethyl sulfoxide (DMSO) and dimethylformamide (DMF) at the stoichiometric ratio of 1:4 (DMSO: DMF). The precursor solution was heated on a hotplate for about $20 \mathrm{~min}$ at $70{ }^{\circ} \mathrm{C}$ along with stirring for the total reaction. $\mathrm{CH}_{3} \mathrm{NH}_{3} \mathrm{I}$ and $\mathrm{PbI}_{2}$ at a stoichiometric ratio of 1:1 were spread on the substrate 
through a spin coater. In this spin coating procedure, $0.1 \mathrm{~m} \mathrm{~L}$ of solution was spun at $2500 \mathrm{rpm}$ for $30 \mathrm{~s}$, while $0.2 \mathrm{~mL}$ ethyl acetate was spun over the film at $2500 \mathrm{rpm}$ for $10 \mathrm{~s}$ after the spin coating commenced. The film was then annealed at $70^{\circ} \mathrm{C}$ on a hotplate for about $10 \mathrm{~min}$ to enable crystallization of the perovskite layer and subsequently cooled to normal temperature. The features and morphology of the perovskite layer depended on the mixture of the precursor, the speed at which the substrate was spun, and the annealing process requirements, such as the annealing time and temperature used for crystallization. The next step was the deposition via spin coating of the $(100 \mu \mathrm{L})$ hole transport layer (HTL) with Spiro-OMeTAD at $3500 \mathrm{rpm}$ for $20 \mathrm{~s}$. To prepare the HTM solution in chlorobenzene, $72.3 \mathrm{mg}$ of Spiro-OMeTAD was mixed with $1 \mathrm{~mL}$ of chlorobenzene. This provided a simplified approach for preparing HTM without using the hydrophilic lithium salt (LiTFSI). Finally, gold $(\mathrm{Au})$ was then deposited through a mask as the top electrode in a high vacuum chamber using thermal evaporation. The active area of the cell was estimated to be $0.04 \mathrm{~cm}^{2}$.

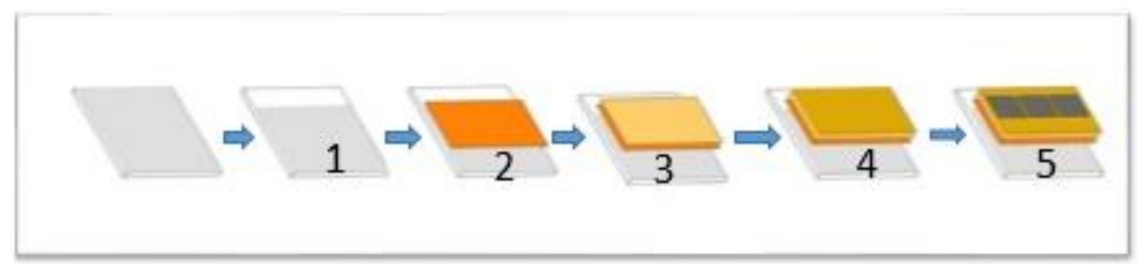

Figure 1. Planar perovskite solar cell fabrication procedures: (1) FTO etching; (2) ZnO deposition; (3) $\mathrm{PbI}_{2}+\mathrm{MAI}+\mathrm{DMSO}$ in DMA deposition; (4) HTL deposition; (5) gold back contact deposition.

\subsection{Thin Film Characterization}

The X-ray diffraction (XRD) measurement was clearly confirmed using a XPert Pro $\mathrm{X}$-ray diffractometer from Panalytical Ltd. (Eindhoven, Netherlands) with $\mathrm{Cu}-\mathrm{K}_{\alpha}$ radiation. Optical absorption profiles were performed using a model lambda 750 Perkin Elmer UV-visible spectrophotometer with wavelengths between 200 and $1400 \mathrm{~nm}$. The photoluminescence (PL) spectrum was measured using a Fluorolog-3 spectrophotometer with an excitation wavelength of $514.5 \mathrm{~nm}$ at normal temperature. An Auriga scanning electron microscope from Zeiss (Berlin, Germany) was used to examine the surface morphology of the film. A Veeco Multimode atomic force microscope (AFM) was used to establish the thickness and roughness of the film.

\subsection{Device Characterization}

Current versus voltage (I-V) measurements of the device were performed under AM $1.5 \mathrm{G}$ illumination at $1000 \mathrm{Wm}^{-2}$ using a solar simulator equipped with a source meter.

Electrochemical impedance spectroscopy (EIS) measurements using a Bio-LogicVMP3 potentiostat-galvanostat, Seyssinet-Pariset, France were performed under 1 sun illumination with different $\mathrm{DC}$ bias voltages ranging from -5.0 to $5.0 \mathrm{~V}$. A small AC voltage perturbation of $5 \mathrm{mV}$ was applied during the measurement at frequencies ranging from $100 \mathrm{mHz}$ to $1 \mathrm{MHz}$. The spectra were fitted using Z-View software, Seyssinet-Pariset, France.

\section{Results}

\subsection{Structural Features and Grain Size}

Figure 2 shows the XRD pattern of the perovskite thin film. The major diffraction peaks situated at $14.1^{\circ}, 28.4^{\circ}, 31.9^{\circ}, 40.6^{\circ}$, and $43.2^{\circ}$ for the $2 \theta$ scan correspond to the miller indices (110), (220), (222), (224), and (314), respectively. These peaks corroborate those for perovskites obtained by other researchers [28-30]. According to the crystal planes produced, we can confirm the formation of perovskite $\left(\mathrm{CH}_{3} \mathrm{NH}_{3} \mathrm{PbI}_{3}\right)$, since the peaks that corresponded to lead iodide and methylamine iodide were not observed and the perovskite film was the crystalline perovskite phase. $X$-ray diffraction affirmed the suitable reaction between $\mathrm{PbI}_{2}$ and $\mathrm{CH}_{3} \mathrm{NH}_{3} \mathrm{I}$. The perovskite crystallinity and the quantity of $\mathrm{PbI}_{2}$ residue are essential to the performance of perovskite solar cells. Excess $\mathrm{PbI}_{2}$ residue would hinder 
injection of electrons from the perovskite to the $\mathrm{ZnO}$ layer, thus limiting the performance of the PSCs.

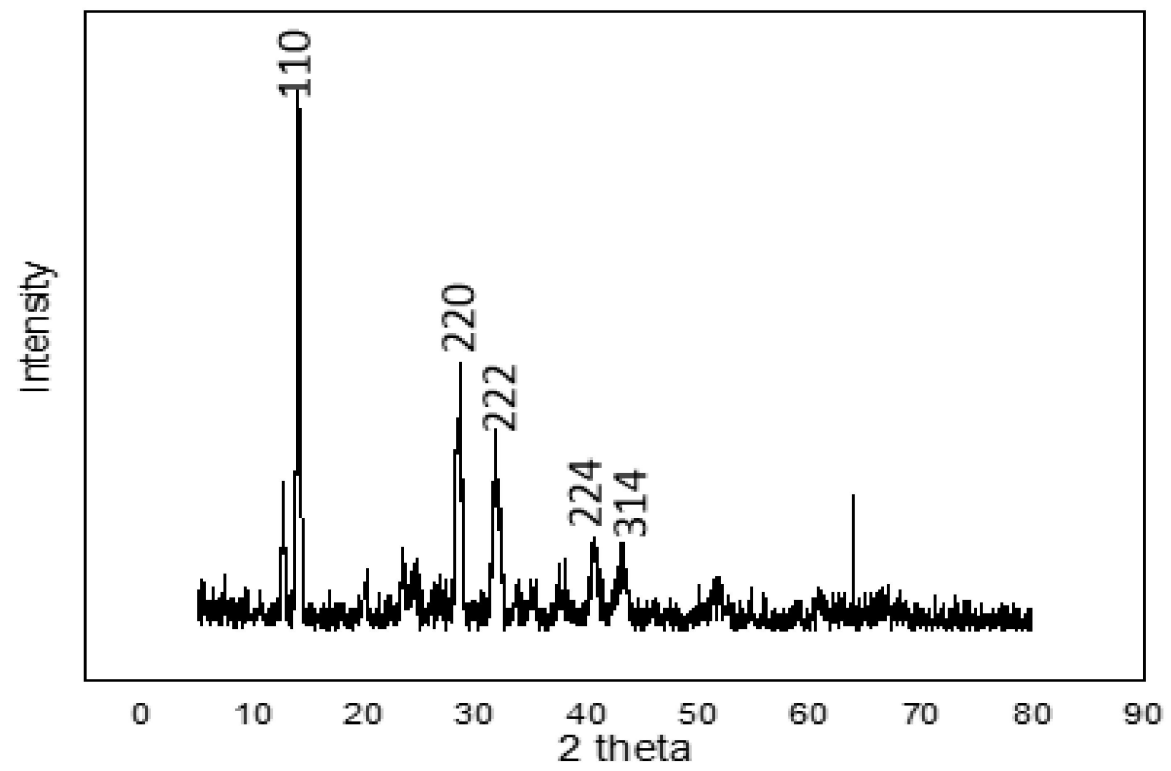

Figure 2. XRD profile of the solution-processed perovskite thin film on FTO glass substrate prepared under ambient conditions.

The grain size was estimated to be $30 \mathrm{~nm}$ according to the Scherrer formula using the calculation technique used in [31,32]. The surface topography of the film as measured using an AFM at a resolution of $30 \times 30 \mu \mathrm{m}^{2}$ to yield an rms roughness of $7.7 \mathrm{~nm}$ is shown in Figure 3. The average height-to-height correlations correspond to the morphological image in Figure 4 for the perovskite film prepared by employing DMSO additive in the solvent. It is, therefore, obvious that the use of ethyl acetate as an antisolvent leads to homogeneous crystallization of the perovskites with minimal pinholes.

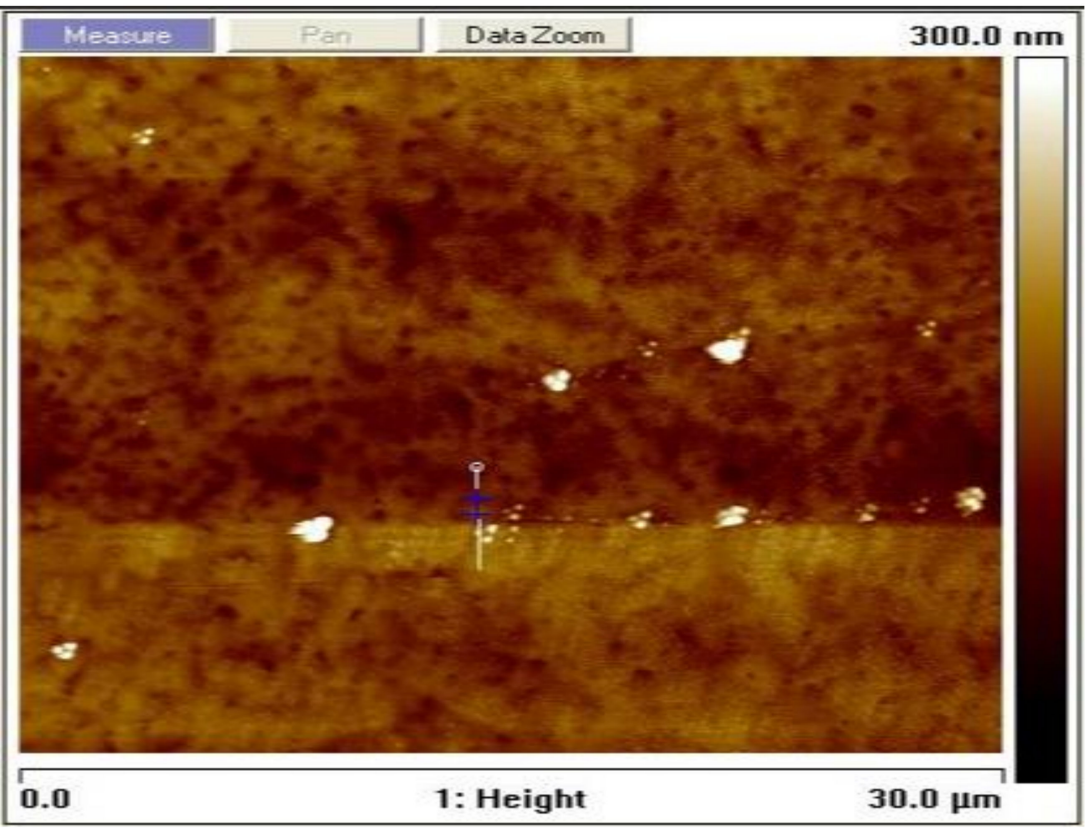

Figure 3. Topographical image of the solution-processed perovskite thin film prepared under ambient conditions. 


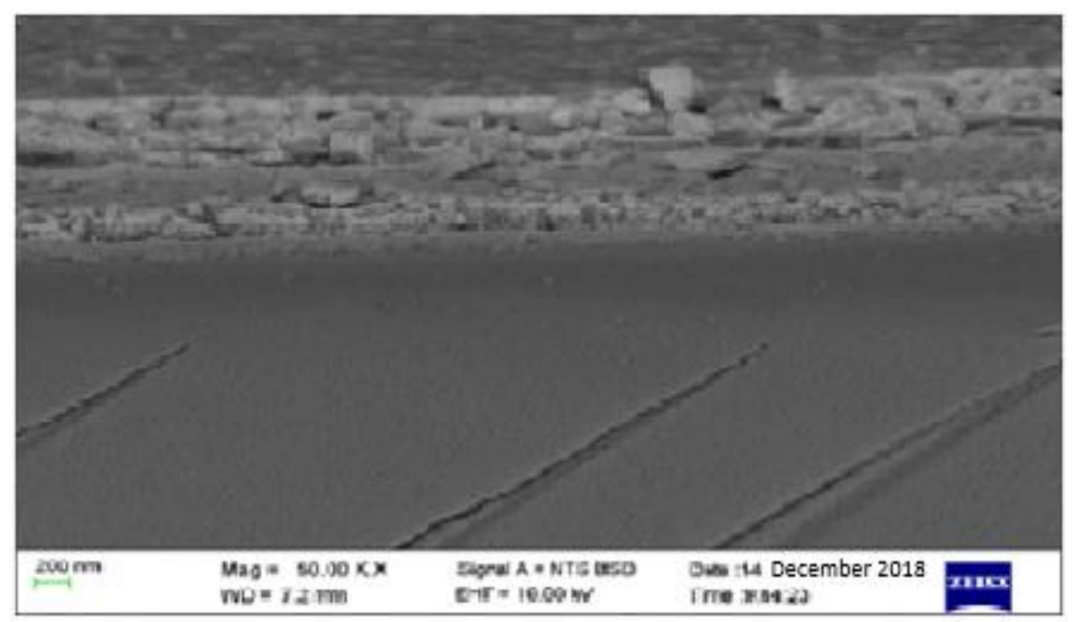

Figure 4. SEM micrograph for the solution-processed perovskite thin film prepared under ambient conditions.

\subsection{Photophysics of Perouskite Polycrystalline Thin Film}

The working principles of PSC are strongly dependent on the quality of the perovskite film. Hence, it is very imperative to investigate the luminescence properties of the film before layer coupling so as to identify the causes and locations of recombination loss within the device. It must also be noted that the best quality film and spectroscopic factual knowledge of intrinsic properties are vital for the development of modern perovskite applications, since basic research usually forms a pillar of technological advancement.

\subsubsection{Transmission and Emission Spectra}

The absorption edge in our hybrid perovskite thin film was located at around $797.50 \mathrm{~nm}$ and corresponded to a bandgap of $1.55 \mathrm{eV}$. The perovskite layer with a thickness of $300 \mathrm{~nm}$ showed that the absorption was in the red and near-IR regions, thus suggesting a potential match to the highest photon flux in the solar emission spectrum. The absorption edge of $\mathrm{CH}_{3} \mathrm{NH}_{3} \mathrm{PbI}_{3}$ displayed in Figure 5 is evidence of the low defect density and step-like absorption, which is necessary for improving solar cells, as stipulated according to the detailed balance theory $[33,34]$. Furthermore, the absorption here exceeds $700 \mathrm{~nm}$ and is a beneficial quality for optoelectronic devices.

There is an absorption edge around $600 \mathrm{~nm}$ that is not as sharp as the one around $800 \mathrm{~nm}$. This implies that the absorption range of lead halide perovskite is not confined to the visible region, as reported in some studies [61]. However, by further enhancing the morphology and composition of perovskite materials, the near-infrared (NIR) photo responses of PSCs can be optimized.

Photoluminescence (PL) provides information on the degree of crystallinity, quantum efficiency, electronic properties, existence of traps and defect states, recombination process, and phase transformation in materials. This information may be derived from the linewidth, intensity, and content of the PL spectrum, as displayed in Figure 5. 


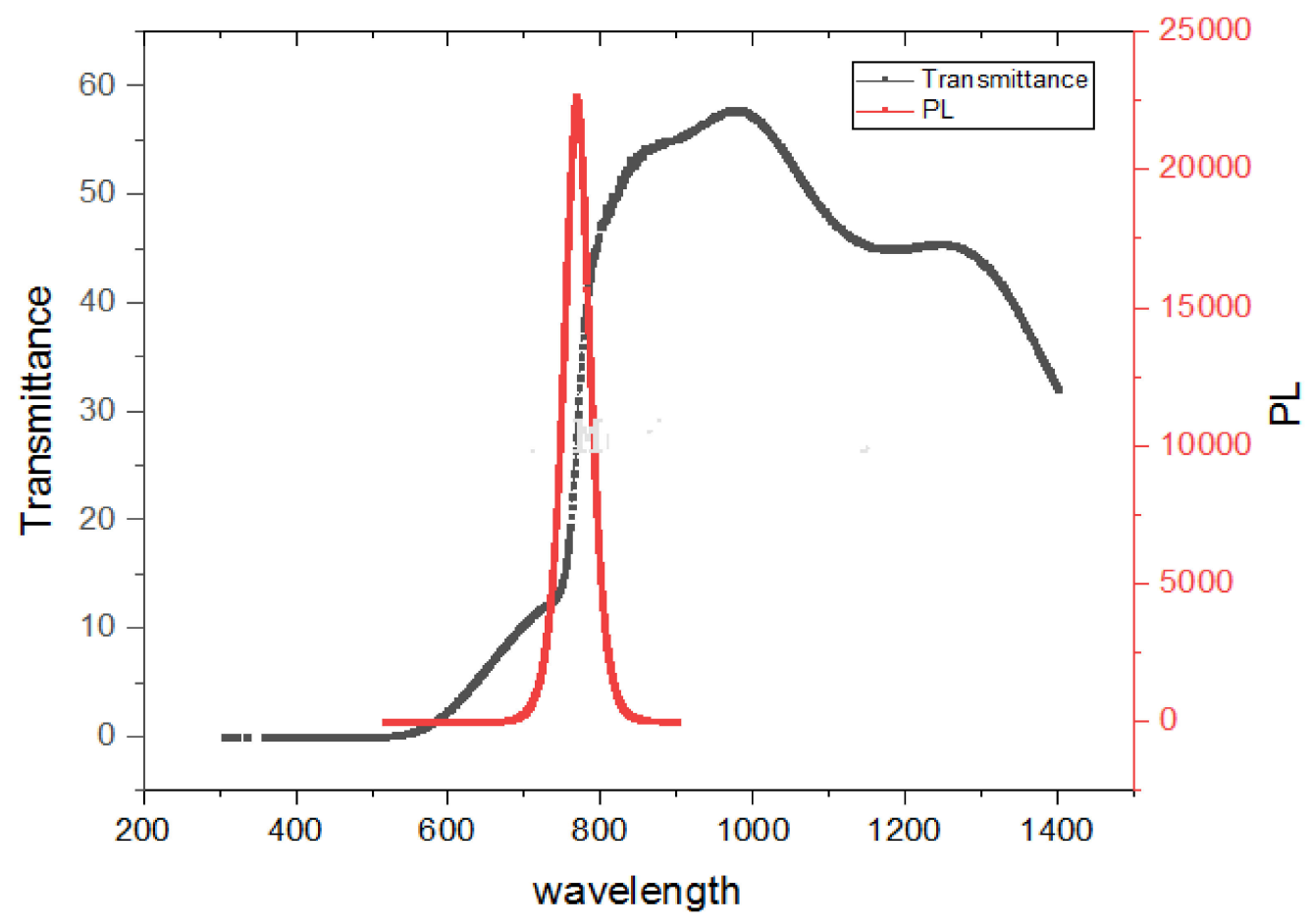

Figure 5. Transmission and PL properties of solution-processed perovskite thin film.

An important measure for defining the optical feature of a material using the PL spectrum is the width of the emission band, as displayed in Figure 5. When the full-width at half-maximum (FWHM) of the PL shows smaller values (789.99 nm-748.16 nm), this is an indication of excellent structural uniformity, such a width of several quantum wells and formation uniformity. The excitation of the thin film using the $514.5 \mathrm{~nm} \mathrm{Ar}^{+}$line showed a main intense peak located at about $769.79 \mathrm{~nm}$ corresponding to band-to-band emission at air temperature. The film with smaller crystallites could reveal better luminescence intensity than for bigger crystallites. This is consistent with the crystallite size obtained from the Scherrer formula. There is no evidence of the quantum confinement effect, since the crystalline domains (as indicated by SEM and XRD) are larger than the recorded Bohr radius (2.2 $\mathrm{nm}$ for $\mathrm{CH}_{3} \mathrm{NH}_{3} \mathrm{PbI}_{3}$ ) [35]. There are two conclusions drawn from the spectrum. First, the sharp peak intensity is an indication of a radiative recombination mechanism (Wannier-Mott excitons). Secondly, the energy of the PL emission (transition energy) is red-shifted by $0.16 \mathrm{eV}$, which is desirable due to the emission (absorption) at longer wavelengths. The observation of the emission band being red-shifted from the absorption edge is commonly attributed to defect states [36], such as structural defects, vacancies, and impurities. Generally, a red-shifted emission peak is as a result of spontaneous radiative recombination inside such trapped states as compared to the shift from the band edge transition, while the passivation procedure can blue shift the PL peak.

\subsubsection{Absorption Coefficient $(\alpha)$}

The absorption coefficient of a material at a particular electromagnetic wave describes energy transfer through carrier excitation. It outlines how a material light of a particular electromagnetic wave can enter before it is absorbed. The absorption coefficient $(\alpha)$ can be calculated using the Beer-Lambert relation in the equation $\alpha=2.303 \times A / t$, where $A$ is the absorbance and $t$ represents the thickness of the thin film.

The absorption is equal to the flow of the charge carriers from the valence to the conduction band, which is used to evaluate the bandgap of the material. In accordance with the absorption, the value of the absorption coefficient $\left(1.84 \times 10^{4} \mathrm{~cm}^{-1}\right)$ was evaluated, similarly to other studies [62]. The absorption of the $\mathrm{MAPbI}_{3}$ film exhibits a strong edge around the wavelength of $797.50 \mathrm{~nm}$, in close agreement with c-Si, GaAs, CIGS, and 
CdTe [37]; thus, very thin films are suitable for PSCs because of the long exciton diffusion lengths, in contrast to the organic semiconductor, which has short exciton diffusion lengths.

\subsubsection{Anti-Stokes Shift}

The unusual occurrence of anti-Stokes shift luminescence, in which photons are emitted with greater energy than absorbed, is clearly shown in Figure 5. The above behavioral pattern seen in Figure 5 affirms that $\mathrm{CH}_{3} \mathrm{NH}_{3} \mathrm{PbI}_{3}$ has almost no defects and the free carriers in the bands regulate the optical responses. It is also suggested that excitons do not seem to be paramount for $\mathrm{CH}_{3} \mathrm{NH}_{3} \mathrm{PbI}_{3}$, which is in agreement with the absorption spectrum displayed in Figure 5. A potential reason for this rare behavioral pattern is that it is the result of homogeneous broadening [38]. A suggestion was made that an effective electron-phonon interplay is responsible for the high anti-stokes PL [39].

In summary, the peculiar anti-Stokes shift suggests a strong electron-phonon coupling in $\mathrm{MAPbI}_{3}$, which may be useful for particular applications, such as up-conversion of nanomaterials and bio-imaging. Our results suggest that optical excitation in perovskite is generated by Wannier-Mott excitation [40], which indicates the creation of free charge carriers responsible for the photovoltaic effect.

\subsection{Photovoltaic Performance Measurement}

The performance of the whole device likewise depends on the interfacial contacts with the charge-extracting materials, following the idea that "the interface is the device".

Measurement of the light intensity dependence of the current-voltage (I-V) was demonstrated to be an effective instrument for pinpointing the prime recombination loss processes in organic photovoltaic (OPV) devices [41-43], which is also applicable to perovskite solar cells.

The solar cell was fabricated and tested on 12 December 2018. To confirm its longterm stability, five months later (6 April 2019), the device was tested again to check its performance and level of stability. The photovoltaic parameters that were collected from the I-V curves in Figures 6 and 7 are summarized in Tables 2 and 3.

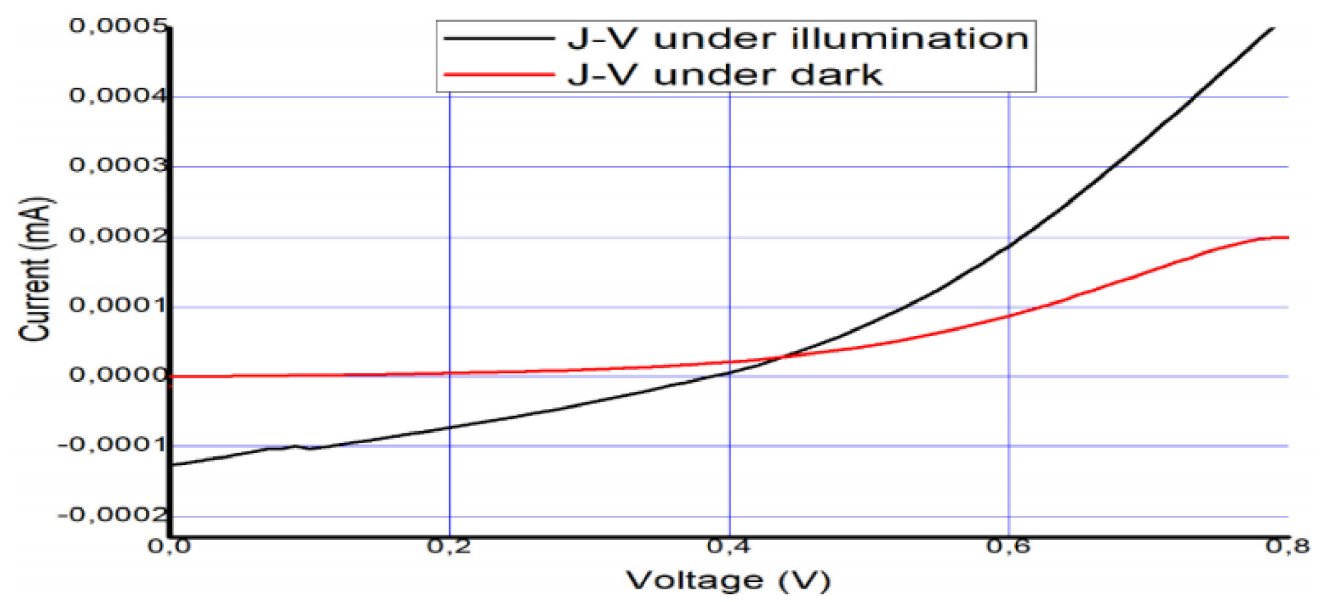

Figure 6. Measured I-V curve of $\mathrm{MAPbI}_{3}$ under AM 1.5 and under dark conditions on 12 December 2018. 


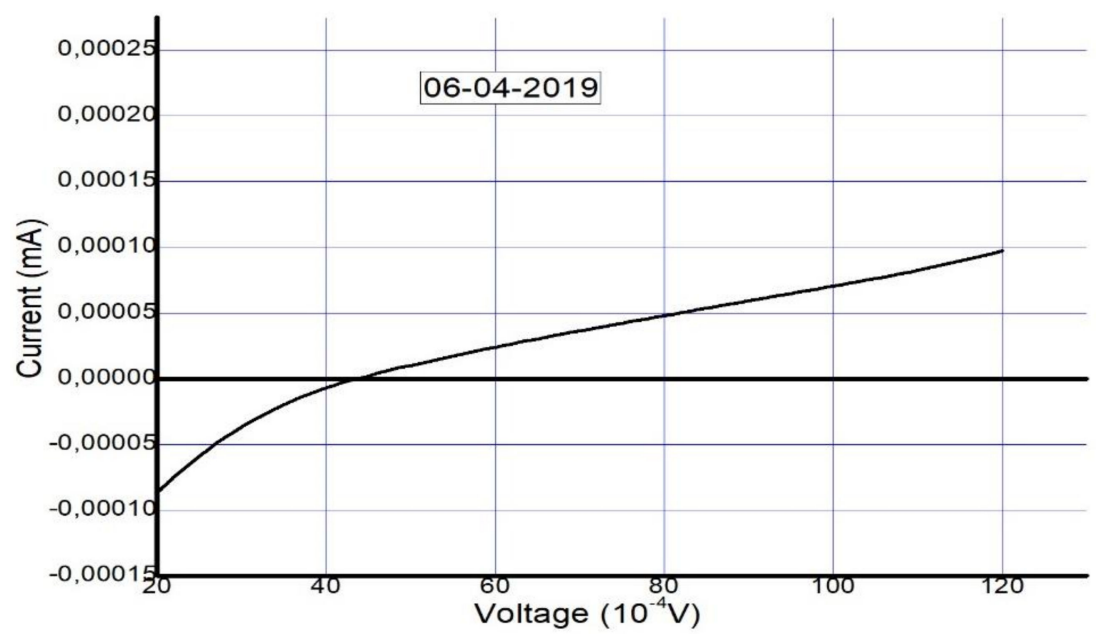

Figure 7. Measured I-V curve of $\mathrm{MAPbI}_{3}$ after five months (on 6 April 2019).

Table 2. Measured cell characteristics and electrical parameters for Figure 6. Measured cell characteristics and electrical parameters of the device just after fabrication and then 5 months later.

(a)

\begin{tabular}{cccccccc}
\hline$V_{\boldsymbol{o c}}$ & $\boldsymbol{J}_{\boldsymbol{s c}}$ & $\boldsymbol{F F}$ & IPCE & APCE & $\boldsymbol{R}_{\boldsymbol{s}}$ & $\boldsymbol{R}_{\text {SH }}$ & $\boldsymbol{\eta}$ \\
\hline $0.39 \mathrm{~V}$ & $3.4 \mathrm{~mA} / \mathrm{cm}^{2}$ & $33 \%$ & $52.8 \%$ & $65.2 \%$ & $71.4 \Omega \mathrm{cm}^{-2}$ & $160.4 \Omega \mathrm{cm}^{-2}$ & $4 \%$ \\
\hline
\end{tabular}

Table 3. Measured cell characteristics and electrical parameters of the device just after fabrication and then 5 months later.

\begin{tabular}{ccccc}
\hline Date & $J_{\boldsymbol{s c}}$ & $\boldsymbol{V}_{\boldsymbol{o c}}$ & $\boldsymbol{F F}$ & $\boldsymbol{\eta}$ \\
\hline 12 December 2018 & $3.4 \mathrm{~mA} / \mathrm{cm}^{2}$ & $0.39 \mathrm{~V}$ & $33 \%$ & $4 \%$ \\
\hline 6 April 2019 & $2.3 \mathrm{~mA} / \mathrm{cm}^{2}$ & $0.0044 \mathrm{~V}$ & $25.4 \%$ & $0.02 \%$ \\
\hline
\end{tabular}

The cell was fabricated under ambient conditions without a glovebox. It was kept under normal conditions without encapsulation. Our aim was to study charge transport mechanisms of the device without using dopants, a glovebox, or encapsulation. This would enable us to gain a better understanding of the working mechanism of the cell.

The performance of the PSCs can be determined from the short circuit current density, the open circuit voltage, and the fill factor (FF). Generally, the FF is highly dependent on the ratio of the magnitudes of series resistance $\left(R_{S}\right)$ and shunt resistance $\left(R_{s h}\right)$.

The equivalent circuit of the PSC is displayed in Figure 8. The output current density $J$ can be stated by Equation (1):

$$
J=J_{0}\left(e^{\frac{q\left(V-J R_{s}\right)}{n K T}}-1\right)+\frac{V-J R_{s}}{R_{s h}}+J_{\mathrm{sc}}
$$

where $J_{0}$ typifies the reverse saturation current density, $n$ is the ideality factor, $K$ is the Boltzmann's constant, $T$ is the temperature, and $q$ is the electron charge. 


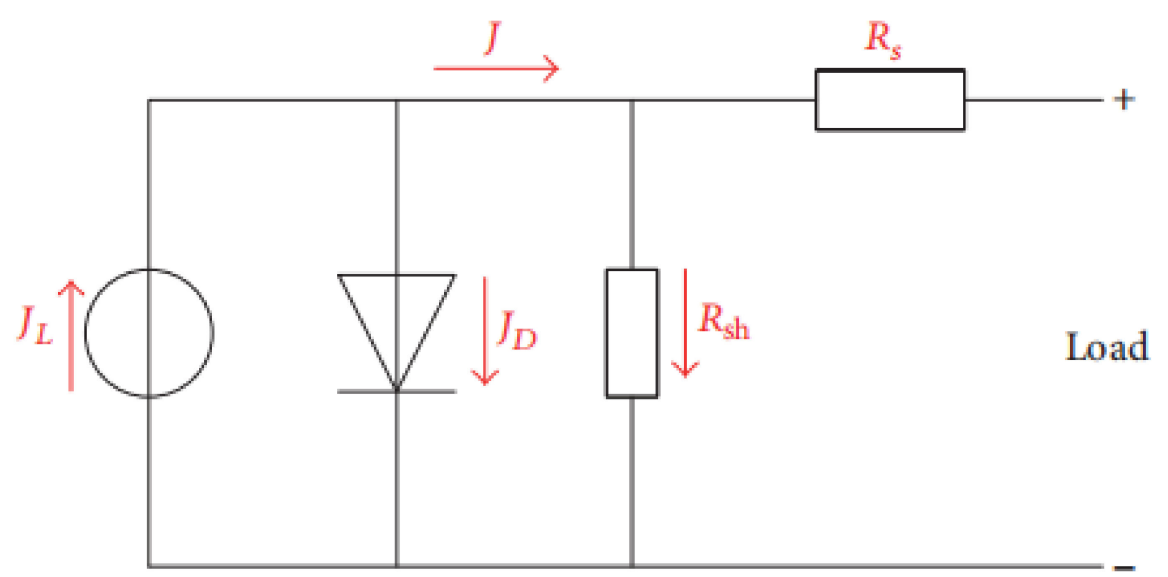

Figure 8. Equivalent circuit of the perovskite solar cell.

The I-V curve after 5 months suggests the presence of a Schottky barrier due to the increase in series resistance. This occurred as a result of the decomposition of the perovskite layer and degradation of the interfacial carrier transport layer, similar to the results in [63]. We take this as evidence of degradation that occurred due to unencapsulation of the device over a long period.

It was observed that the series resistance $R_{S}$ conveys the entire conductivity of the device, which is strongly correlated with its internal carrier mobility, while the shunt resistance $R_{s h}$ applies to the loss of photogenerated charges during carrier recombination inside the device, especially at layer interfaces.

The high $R_{S}$ value implies that the interphase contact was small with high recombination and low hole mobility in the HTM, which means a low photocurrent would be produced.

$R_{s h}$ is intimately connected with the charge recombination at interfaces within solar cells. A lesser charge recombination results from a higher $R_{s h}$, and vice versa. The low shunt resistance suggests that the power loss in the solar cell across the alternate current path was very high, leading to low FF and electron mobility.

To further evaluate the performance of our hybrid PSC, the following photovoltaic parameters were determined. The incident photon to current conversion efficiency (IPCE) was calculated using the relation IPCE\% $=1240\left(J_{s c} / \operatorname{Pin} \lambda\right)$. Here, an IPCE of 52.8\% was obtained, which suggests that the $\mathrm{ZnO}$-perovskite heterojunction utilizes the advantages of each component. This includes the improved light absorption of $\mathrm{CH}_{3} \mathrm{NH}_{3} \mathrm{PbI}_{3}$ and fast electron transfer of $\mathrm{ZnO}$. Hence, the size of the IPCE, also known as the external quantum efficiency (EQE), relies on the level of light absorption by the solar cell and how much of the absorbed light is transformed to charge carriers, which are extracted. This is why the IPEC is usually affected by reflection and external loss of the photons.

The internal quantum efficiency (IQE), also known as the absorbed photon to current conversion efficiency (APCE), serves as a measure of the inherent performance of a device, including its charge separation and charge injection efficiency. The IQE is usually higher than the EQE. A small IQE shows that the active layer of the solar cell cannot effectively utilize the photons. The equation for the APCE is given as follows: APCE $=\mathrm{EQE} / 1$ - reflection.

Our solar cell showed better stability and great light harvesting and charge separation efficiency, although the conversion efficiency was reduced due to the thickness of the perovskite layer, as well as certain other factors that will be discussed in the next section. The values of $V_{o c}$ and $J_{s c}$ obtained could be related to the low hole mobility in the hole transport material due to the absence of lithium salt and interfacial recombination loss, resulting in low efficiency. 


\subsection{Impedance Response of Planar Perouskite Solar Cell}

To gain insight into the separation of light-induced charges and recombination at the interfaces, we conducted EIS measurements and ideality factor measurements on the device.

The dynamic response of any solar cell is determined by various fundamental processes, including charge transport, charge storage, electron hole recombination, and interfacial charge transfer. Each of these processes can be reflected in the impedance response. The EIS measurements address charge extraction, which controls short-circuit conditions and charge recombination, which in turn determine the open-circuit conditions, allowing for complete investigation of the solar cell. From the Nyquist plot in Figure 9a, the high and low frequency impedance characteristics were observed while testing the FTO-ZnOperovskite-Spiro-OMeTAD-Au device.

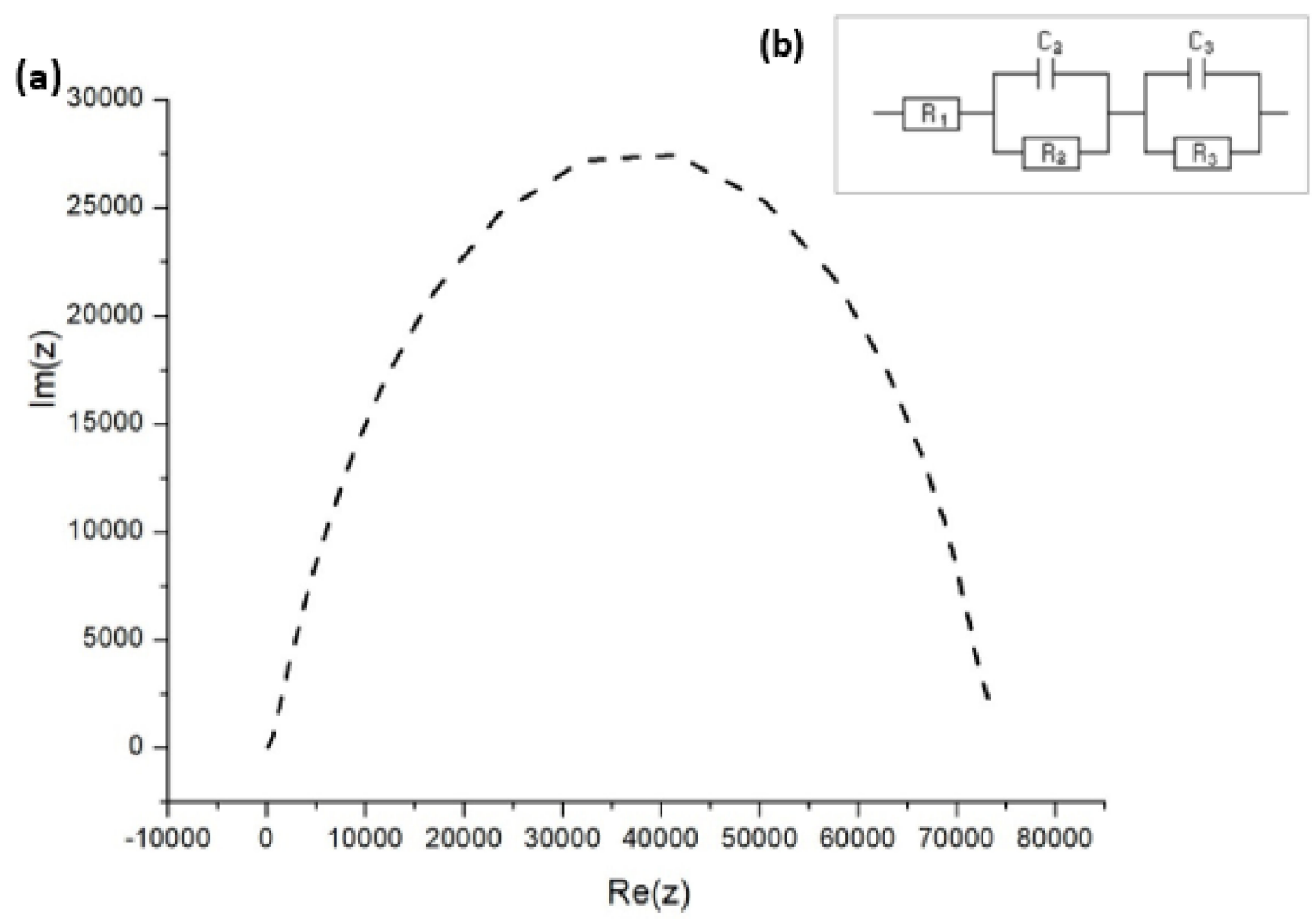

Figure 9. (a) Nyquist impedance spectrum for FTO-ZnO-perovskite-Spiro-OMeTAD-Au device. (b) EIS equivalent circuit employed to fit the impedance response.

An equivalent circuit in Figure $9 \mathrm{~b}$ was employed to fit the data in the Nyquist plots, the respective fitting parameters for which are provided in Table $4 . R_{1}$ is the series resistance of the cell, $C_{3}=C \mu$ is the chemical capacitance of the cell, and $R_{3}$ is the recombination resistance. $C_{2}$ and $R_{2}$ are respectively the capacitance and resistance of hole transport materials [44,45]. The equivalent circuit model that we adopted has been used extensively to explain the EIS data of PSCs made using the solution process $[46,47]$.

Table 4. Measured impedance parameters of the fabricated perovskite solar cell.

\begin{tabular}{ccccc}
\hline $\mathbf{R}_{\mathbf{1}}(\boldsymbol{\Omega})$ & $\mathbf{R}_{\mathbf{2}}(\boldsymbol{\Omega})$ & $\mathbf{R}_{\mathbf{3}}(\mathbf{k} \Omega)$ & $\mathbf{C}_{\mathbf{2}}(\mathbf{n F})$ & $\mathbf{C}_{\mathbf{3}}(\mathrm{nF})$ \\
\hline 63.16 & 325.1 & 44.341 & 3.612 & 91.39 \\
\hline
\end{tabular}

In our experiments (Figure 9a), the diffusion (that is, Warburg diffusion) of the charge carriers was not observed, which was indicative of two separate impedance indicators: the recombination resistance $R_{\text {rec }}$ and the trap-dominated chemical capacitance $C_{\mu}$. There was 
no information at all with respect to electron transport. There are two possibilities why the Warburg part was absent: the first one is that the conductivity was extremely high and transport resistance became drastically low, while the second possibility is that the presence of the electron transport layer (ETL) network attributed to the very thin $\mathrm{ZnO}$ film [48]. Carriers generated in thin layer do not have to diffuse for long before they can be collected at the junction. Therefore, very thin layers would lead to the loss of long-wavelength photon absorption, reducing the photocurrent. The lack of the transport resistance feature in Figure 9a is thought to account for the high diffusion rates and mobilities described for charges in hybrid perovskite materials [49,50].

The capacitive components are expressly shown in the established illustration as being related to the dielectric constant of perovskite and to the surface charge build-up at the interface. The $C_{2}$ predominates the capacitive feedback in the high-frequency section of the spectrum and relates to the separation of charges between the perovskite layer and neighboring interfacial materials, while $C_{3}$ responds to the well-known low-frequency process that controls the solar cell operation.

Regarding the operating mechanism for the perovskite solar cells on the basis of EIS, the impedance indicators, such as the time constants, resistances, and capacitances, were analyzed. Table 5 shows the impedance parameters to further explain the dynamic processes within the device. Ideally, one can calculate two isolated time constants as the products $\tau_{H}=R_{2} C_{2}$ and $\tau_{L}=R_{3} C_{3}$. These time constants are related to the high- and low-frequency arcs, as long as $C_{3}>>C_{2}$, which applied in our case.

Table 5. Impedance parameters of the fabricated perovskite solar cell.

\begin{tabular}{ccccc}
\hline$\tau_{\mathbf{H}}$ & $\boldsymbol{\tau}_{\mathbf{L}}$ & $\mathbf{L}_{\mathbf{n}}$ & $\mathbf{D}_{\mathbf{n}}$ & $\boldsymbol{\mu}$ \\
\hline $1.17 \mu \mathrm{s}$ & $4.05 \mathrm{~ms}$ & $9.1 \mu \mathrm{m}$ & $32.63 \mathrm{~nm}^{2} / \mathrm{s}$ & $0.003 \mathrm{~cm}^{2} / \mathrm{Vs}$ \\
\hline
\end{tabular}

The shorter time constant $\tau_{H}$ keeps the trend marked by $R_{2}$. Considering $C_{2}$ is uncoupled from the resistive element $R_{2}$, the respective time constant cannot be considered as a characteristic time of any physical mechanism. Conversely, the longer time constant $\tau_{L}$ shows light-independent values during both short- and open-circuit conditions. The light-independent behavior and the same level of magnitude of these time constants are clear signals of the coupling between $R_{3}$ and $C_{3}$ in a usual kinetic process. In addition to this, $\tau_{H}$ cannot be appropriately regarded as a carrier lifetime due to the fact that $C_{2}$ is not a chemical capacitance [51]. At the same time, the electron time constant, $\tau_{L}$, is attributed to the electrons at the interface. Based on the results, the resistive elements follow the inverse relationship pattern with the light intensity, with the low-frequency resistance $R_{3}$ exhibiting a bigger value than the high-frequency contribution $R_{2}$. Similarly, capacitive elements also confirm the inverse variation with light intensity. Hence, we argue that resistive components, as well as cumulation capacitance, behave in the reverse manner with irradiation intensity and bring us to the conclusion that both originate from the usual process.

\subsection{Determination of the Basic Transport Coefficients/Parameters}

Electron or hole transport is determined by a gradient of the Fermi level and the transport in the semiconductor, hence creating a loss of free energy of the carriers. Moreover, the collection of carriers to create a photocurrent in the external circuit is competing with recombination mechanisms. Therefore, it is vital to assess and measure the energy losses related to the diffusion length and carrier transport; to this effect, the following fundamental transport coefficients of the electronic carriers, such as the mobility and the diffusion coefficient, $D_{n}$, were established in this study. In addition, the transport resistance, $r_{t}$, is the main parameter that explains the transport features in EIS. A narrative approach to obtain $D_{n}$ from $r_{t}$ is presented below. 
The electron diffusion coefficient $\left(D_{n}\right)$ can be represented by the following equation: $D n=\mathrm{d}^{2} / 235 \mathrm{t}_{\mathrm{H}}$. The time constants determined can, thus, be employed to calculate the electron diffusion length $(L n)$, which is given by $L n=\left(D_{n} t_{s}\right)^{1 / 2}$. The conductivity can be given in the form of the chemical diffusion coefficient and the chemical capacitance as on $=C_{\mu} D_{\mathrm{n}}$.

Mobility $(\mu)$ is the basic quantity that decides the diffusion length, given as $L=\sqrt{ } D \tau$, where $D$ is the diffusion coefficient, given as: $D=\mu q / k_{\mathrm{B}} T, q$ is the elementary charge, $k_{\mathrm{B}}$ is the Boltzmann constant, and $T$ is the temperature.

We show that the electron diffusion length is greater than $1 \mu \mathrm{m}$, which is one of the most reported values for 3D perovskite polycrystalline films [52] and much longer than that of the low-dimensional perovskite [53]. This superior carrier diffusion length originated from the enhanced 3D perovskite stability without a dopant. The charge carrier mobility contributes significantly in charge extraction to the electrodes. Delaying charge mobility may enhance the potential for recombination, being accountable for lowering $V_{o c}$. This suggests that the mobility plays an important role in managing $V_{o c}$.

\subsection{Charge Injection Mechanism and Recombination}

In this work, we fabricated the n-i-p device structure. The energy band diagram of the fabricated perovskite solar cell employed in our investigation is depicted in Figure 10. The perovskite layer is the light-absorbing material that generates the charge separation, pushing electrons to the $n-i$ junction and holes to the $\mathrm{i}-\mathrm{p}$ junction. Our findings from ideality factor and impedance spectroscopy suggest the presence of nonradiative recombination across the bandgap, leading to suppression of $J_{s c}$. Furthermore, the suppression of $V_{o c}$ could be a result of delayed charge mobility at the perovskite-spiro-OmeTAD interface due to the absence of lithium salt in spiro-OmeTAD.

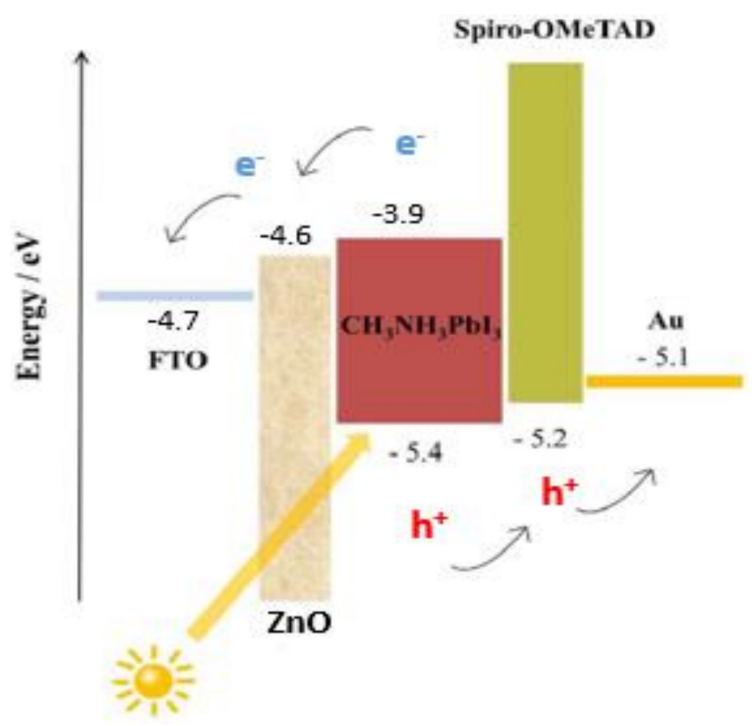

Figure 10. Energy band diagram of the fabricated perovskite solar cell structure, consisting of an FTO electrode, $\mathrm{ZnO}$ electron transport layer, light-absorbing $\mathrm{MAPbI}_{3}$, spiro-OMeTAD hole transport layer, and gold contact.

The major junction determinant that governs the charge injection mechanism is the barrier potential, which therefore is always mostly regulated via defects, interface dipoles, Fermi level alignments [54], energetic disorder provided by the roughness at metal-organic semiconductor contacts [55], and defects. In some cases, image force also contributes by generating current backflow [56]. Furthermore, the ideality factor $(n)$ is one of the diode I-V characteristic parameters. It is an indicator of charge recombination mechanisms within the semiconductor diode. If the recombination of electrons and holes occurs within the bandgap (i.e., direct recombination or bimolecular recombination), the diode ideality factor 
is $n=1$, while the ideality factor of 2 is defined as recombination through defect traps; that is, recombination centers [57]. Diode ideality factors greater than 2 are rare. A possible reason for such high ideality factors is a high rate of interfacial recombination [58-60]. The ideality factor influences the fill factor of the solar cell, as an increase in $n$ leads to a decrease in the fill factor. This is why the initial approach to the source of the charge recombination that takes place in a device can be considered by checking the ideality factor.

Additional study is required into the connections between ionic arrangements and recombination. Apparently, interfacial properties control the operation of the device. In light of this, we considered the effects of the interfacial carrier injection process and the recombination mechanism by bringing focus onto the basic interface physics responsible for the observed efficiency of the perovskite solar cell. The usual method used to obtain the barrier height and ideality factor is to plot the $\ln I$ versus the voltage $V$, as explained below. The ideality factor of the device was calculated using the slope of the linear section (the exponential region of the forward bias of the $\ln I(V)$ characteristics of the plot shown in Figure 11. The slope, which is equivalent to $d v / d(\ln I)$, was utilized in Equation (2) to establish n:

$$
n=\frac{q}{K T} \frac{\Delta V_{F}}{\Delta\left(\ln I_{F}\right)}
$$

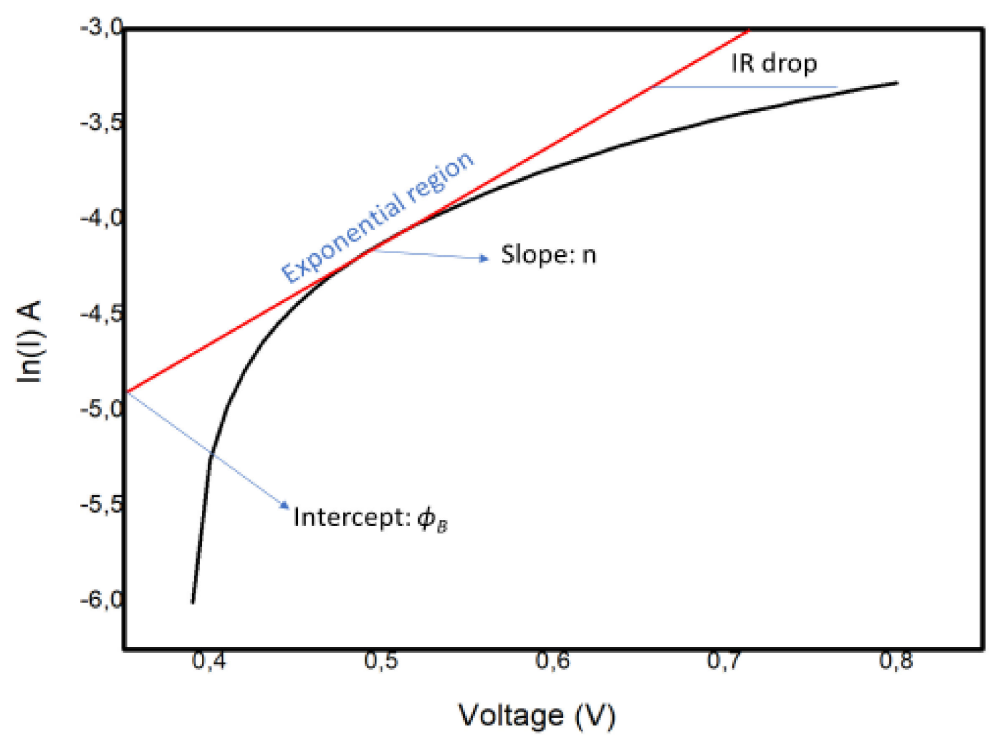

Figure 11. The $\ln \mathrm{I}-\mathrm{V}$ characteristics for the Schottky barrier junction type in the FTO-ZnOperovskite-Spiro-OmeTAD-Au device.

The value of the energy barrier was calculated from the forward bias I-V characteristics using Equation (3), in which $A$ * is the Richardson constant:

$$
\phi_{B}=-\frac{K T}{q} \ln \frac{J_{s}}{A * T^{2}}
$$

Here, we investigated the potential barrier $\phi_{B}$ (also known as the Schottky barrier) and ideality factor $(n)$ of the device.

The graph shows a nonideal curve, since a perfect straight line slope was not obtained. The possible explanations for the nature of the curve could be the following:

- The presence of multiple transport mechanisms, such as quantum mechanical tunnelling through the barrier and current leakage across the contact perimeter, which may have altered the linear section of the $\ln I-V$ plot, hence making it difficult to extract the saturation current and other parameters;

- The high $R_{S}$ value, which may have increased the magnitude of the ideality factor. 
The values of $\phi_{B}=0.20 \mathrm{~V}$ and $n=3.3$ were determined from the semilog $I-V$ plot in Figure 11. In our case, the interfacial recombination was dominant, since the value was 3.3. This suggests a negative impact on the transport process at the interface, in turn affecting the overall efficiency of the cell. This is consistent with impedance spectroscopy findings indicating that recombination occurred at the interfaces.

\section{Conclusions}

In summary, having demonstrated the impacts of interfacial recombination through ideality factor measurements (I-V curves) and small-perturbation measurement techniques (EIS), the absence of dopants in our (hybrid) perovskite semiconductor increased the longevity of the device and simplified the charge transport mechanism. In our study, the absorption and charge transport process were satisfactorily investigated. However, the final mechanism, which is the extraction of the photogenerated charge at interface, was problematic. In order to successfully suppress the recombination, especially at interface, energy alignment and suppression of nonradiative defect recombination at the interface with a dopant that is not vulnerable to degradation are recommended. Lastly, the use of the planar architecture for investigation affords a clearer picture of the charge transfer mechanism in perovskite solar cells.

Author Contributions: S.A.O. conceived the original idea and was in charge of the overall direction and experimental analysis. J.K.K. and L.J. aided in interpreting the results and worked on the manuscript. D.W. provided critical feedback, aided in interpreting and helped shape the research, analysis, and manuscript. K.R. and B.M. provided useful information and suggestions for this paper and contributed to the analysis tools. R.E. assisted with optical (UV and PL) measurements. A.S. assisted with electrical measurements. All authors have read and agreed to the published version of the manuscript.

Funding: This research received no external funding.

Institutional Review Board Statement: Not Applicable.

Informed Consent Statement: Not Applicable.

Data Availability Statement: The data presented in this study can be obtained from the corresponding author.

Acknowledgments: We acknowledge the support from the Council for Scientific and Industrial Research (CSIR) and the University of Venda as well as financial support from the National Research Foundation (NRF), South Africa.

Conflicts of Interest: The authors declare that there are no conflict of interest regarding the publication of this article.

\section{References}

1. Fan, J.; Jia, B.; Gu, M. Perovskite-based low-cost and high-efficiency hybrid halide solar cells. Photonic Res. 2014, 2, 111-120. [CrossRef]

2. Kanemitsu, Y.; Handa, T. Photophysics of metal halide perovskites: From materials to devices. Jpn. J. Appl. Phys. 2018, 57, 090101. [CrossRef]

3. Salado, M.; Calió, L.; Contreras-Bernal, L.; Idígoras, J.; Anta, J.A.; Ahmad, S.; Kazim, S. Understanding the In-fluence of Interface Morphology on the Performance of Perovskite Solar Cells. Materials 2018, 11, 1073. [CrossRef] [PubMed]

4. Kazim, S.; Nazeeruddin, M.K.; Grätzel, M.; Ahmad, S. Perovskite as Light Harvester: A Game Changer in Photovoltaics. Angew. Chem. Int. Ed. 2014, 53, 2812-2824. [CrossRef]

5. Shao, S.; Loi, M.A. The Role of the Interfaces in Perovskite Solar Cells. Adv. Mater. Interfaces 2019, 7. [CrossRef]

6. Sutherland, B.R.; Hoogland, S.; Adachi, M.M.; Kanjanaboos, P.; Wong, C.T.O.; McDowell, J.J.; Xu, J.; Voznyy, O.; Ning, Z.; Houtepen, A.J.; et al. Perovskite Thin Films via Atomic Layer Deposition. Adv. Mater. 2015, 27, 53-58. [CrossRef] [PubMed]

7. Cho, K.T.; Paek, S.; Grancini, G.; Carmona, C.R.; Gao, P.; Lee, Y.H.; Nazeeruddin, M.K. Highly effificient perovskite solar cells with a compositional engineered perovskite/hole transporting material interface. Energy Environ. Sci. 2017, 10, 621-627. [CrossRef]

8. Hwang, I.; Jeong, I.; Lee, J.; Ko, M.J.; Yong, K. Enhancing Stability of Perovskite Solar Cells to Moisture by the Facile Hydrophobic Passivation. ACS Appl. Mater. Interfaces 2015, 7, 17330-17336. [CrossRef] 
9. Bhachu, D.S.; Scanlon, D.O.; Saban, E.J.; Bronstein, H.; Parkin, I.P.; Carmalt, C.J.; Palgrave, R. Scalable Route to CH3NH3PbI3 Perovskite Thin Films by Aerosol Assisted Chemical Vapor Deposition. J. Mater. Chem. A 2015, 3, 9071-9073. [CrossRef]

10. Zhou, D.; Zhou, T.; Tian, Y.; Zhu, X.; Tu, Y. Perovskite-Based Solar Cells: Materials, Methods, and Future Perspectives. J. Nanomater. 2018, 2018, 1-15. [CrossRef]

11. Kirchartz, T.; Staub, F.; Rau, U. Impact of Photon Recycling on the Open-Circuit Voltage of Metal Halide Perovskite Solar Cells. ACS Energy Lett. 2016, 1, 731-739. [CrossRef]

12. Głowienka, D.; Zhang, D.; Di Giacomo, F.; Najafi, M.; Veenstra, S.; Szmytkowski, J.; Galagan, Y. Role of surface recombi-nation in perovskite solar cells at the interface of $\mathrm{HTL} / \mathrm{CH}_{3} \mathrm{NH}_{3} \mathrm{PbI}$. Nano Energy 2020, 67, 104186. [CrossRef]

13. Sherkar, T.S.; Momblona, C.; Gil-Escrig, L.; Ávila, J.; Sessolo, M.; Bolink, H.J.; Koster, L.J.A. Recombination in Perovskite Solar Cells: Significance of Grain Boundaries, Interface Traps, and Defect Ions. ACS Energy Lett. 2017, 2, 1214-1222. [CrossRef] [PubMed]

14. Shao, Y.; Fang, Y.; Li, T.; Wang, Q.; Dong, Q.; Deng, Y.; Yuan, Y.; Wei, H.; Wang, M.; Gruverman, A.; et al. Grain boundary dominated ion migration in polycrystalline organic-inorganic halide perovskite films. Energy Environ. Sci. 2016, 9, 1752-1759. [CrossRef]

15. Wu, X.; Trinh, M.T.; Niesner, D.; Zhu, H.; Norman, Z.; Owen, J.S.; Yaffe, O.; Kudisch, B.J.; Zhu, X.-Y. Trap states in lead iodide perovskites. J. Am. Chem. Soc. 2015, 137, 2089-2096. [CrossRef] [PubMed]

16. Sproul, A.B. Dimensionless solution of the equation describing the effect of surface recombination on carrier decay in semiconductors. J. Appl. Phys. 1994, 76, 2851-2854. [CrossRef]

17. Wen, X.; Chen, W.; Yang, J.; Ou, Q.; Yang, T.; Zhou, C.; Lin, H.; Wang, Z.; Zhang, Y.; Conibeer, G.J.; et al. Role of Surface Recombination in Halide Perovskite Nanoplatelets. ACS Appl. Mater. Interfaces 2018, 10, 31586-31593. [CrossRef]

18. Wang, J.; Fu, W.; Jariwala, S.; Sinha, I.; Jen, A.K.-Y.; Ginger, D.S. Reducing surface recombination velocities at the electrical contacts will improve perovskite photovoltaics. ACS Energy Lett. 2019, 4, 222-227. [CrossRef]

19. Idígoras, J.; Contreras-Bernal, L.; Cave, J.M.; Courtier, N.E.; Barranco, A.; Borras, A.; Sanchez-Valencia, J.A.; Anta, J.A.; Walker, A.B. The role of surface recombination on the performance of perovskite solar cells: Effect of morphology and crystalline phase of $\mathrm{TiO}_{2}$ contact. Adv. Mater. Interfaces 2018, 5, 1801076. [CrossRef]

20. Tress, W. Perovskite Solar Cells on the Way to Their Radiative Efficiency Limit-Insights into a Success Story of High Open-Circuit Voltage and Low Recombination. Adv. Energy Mater. 2017, 7, 1602358. [CrossRef]

21. Stolterfoht, M.; Wolff, C.M.; Márquez, J.A.; Zhang, S.; Hages, C.J.; Rothhardt, D.; Albrecht, S.; Burn, P.L.; Meredith, P.; Unold, T.; et al. Visualization and suppression of interfacial recombination for high-efficiency large-area pin perovskite solar cells. Nat. Energy 2018, 3, 847-854. [CrossRef]

22. Stolterfoht, M.; Wolff, C.M.; Amir, Y.; Paulke, A.; Perdigón-Toro, L.; Caprioglio, P.; Neher, D. Approaching the fill factor Shockley-Queisser limit in stable, dopant-free triple cation perovskite solar cells. Energy Environ. Sci. 2017, 10, 1530-1539. [CrossRef]

23. Tress, W.; Yavari, M.; Domanski, K.; Yadav, P.; Niesen, B.; Correa Baena, J.P.; Hagfeldt, A.; Graetzel, M. Inter-pretation and evolution of open-circuit voltage, recombination, ideality factor and subgap defect states during reversible light-soaking and irreversible degradation of perovskite solar cells. Energy Environ. Sci. 2018, 11, 151. [CrossRef]

24. Yang, W.S.; Park, B.-W.; Jung, E.H.; Jeon, N.J.; Kim, Y.C.; Lee, D.U.; Shin, S.S.; Seo, J.; Kim, E.K.; Noh, J.H.; et al. Iodide management in formamidinium-lead-halide-based perovskite layers for efficient solar cells. Science 2017, 356, 1376-1379. [CrossRef]

25. O’Regan, B.C.; Barnes, P.R.F.; Li, X.; Law, C.; Palomares, E.; Marin-Beloqui, J.M. Optoelectronic Studies of Methylammonium Lead Iodide Perovskite Solar Cells with Mesoporous $\mathrm{TiO}_{2}$ : Separation of Electronic and Chemical Charge Storage, Understanding Two Recombination Lifetimes, and the Evolution of Band Offsets during J-V Hysteresis. J. Am. Chem. Soc. 2015, 137, 5087-5099. [CrossRef]

26. Dualeh, A.; Moehl, T.; Tetreault, N.; Teuscher, J.; Gao, P.; Nazeeruddin, M.K.; Gratzel, M. Impedance spec-troscopic analysis of lead iodide perovskite-sensitized solid-state solar cells. ACS Nano 2014, 8, 362-373. [CrossRef]

27. Giordano, F.; Abate, A.; Correa Baena, J.P.; Saliba, M.; Matsui, T.; Im, S.H.; Zakeeruddin, S.M.; Nazeeruddin, M.K.; Hagfeldt, A.; Graetzel, M. Enhanced electronic properties in mesoporous $\mathrm{TiO}_{2}$ via lithium doping for high-efficiency perovskite solar cells. Nat. Commun. 2016, 7, 10379. [CrossRef]

28. Sun, S.; Salim, T.; Mathews, N.; Duchamp, M.; Boothroyd, C.; Xing, G.; Sum, T.C.; Lam, Y.M. The origin of high efficiency in low-temperature solution-processable bilayer organometal halide hybrid solar cells. Energy Environ. Sci. 2014, 7, $399-407$. [CrossRef]

29. Yang, F.; Kamarudin, M.A.; Zhang, P.; Kapil, G.; Ma, T.; Hayas, S. Enhanced Crystallization by Methanol Additive in Antisolvent for Achieving High-Quality $\mathrm{MAPbI}_{3}$ Perovskite Films in Humid Atmosphere. ChemSusChem. 2018, 11, 2348-2357. [CrossRef]

30. Huang, P.-H.; Wang, Y.-H.; Ke, J.-C.; Huang, C.-J. The Effect of Solvents on the Performance of CH3NH3PbI3 Perovskite Solar Cells. Energies 2017, 10, 599. [CrossRef]

31. Yang, Y.; Ri, K.H.; Mei, A.Y.; Liu, L.F.; Hu, M.; Liu, T.F.; Li, X.; Han, H.W. The size effect of $\mathrm{TiO}_{2}$ na-noparticles on a printable mesoscopic perovskite solar cell. J. Mater. Chem. A 2015, 3, 9103-9107. [CrossRef]

32. Lv, M.; Dong, X.; Fang, X.; Lin, B.; Zhang, S.; Xu, X.; Ding, J.; Yuan, N. Improved photovoltaic performance in perovskite solar cells based on $\mathrm{CH}_{3} \mathrm{NH}_{3} \mathrm{PbI}_{3}$ films fabricated under controlled relative humidity. RSC Adv. 2015, 5, 93957-93963. [CrossRef]

33. Shockley, W.; Queisser, H.J. Detailed Balance Limit of Efficiency of pn Junction Solar Cells. J. Appl. Phys. 1961, 32, 510. [CrossRef] 
34. Rau, U.; Werner, J.H. Radiative efficiency limits of solar cells with lateral band-gap fluctuations. Appl. Phys. Lett. 2004, 84, 3735-3737. [CrossRef]

35. Tanaka, K.; Takahashi, T.; Ban, T.; Kondo, T.; Uchida, K.; Miura, N. Comparative study on the excitons in lead-halide-based perovskite-type crystals $\mathrm{CH}_{3} \mathrm{NH}_{3} \mathrm{PbBr}_{3} \mathrm{CH}_{3} \mathrm{NH}_{3} \mathrm{PbI}$. Solid State Commun. 2003, 127, 619-623. [CrossRef]

36. Nandakumar, P.; Vijayan, C. Optical absorption and photoluminescence studies on CdS quantum dots in Nafion. J. Appl. Phys. 2002, 91, 1509-1514. [CrossRef]

37. De Wolf, S.; Holovsky, J.; Moon, S.J.; Löper, P.; Niesen, B.; Ledinsky, M.; Haug, F.J.; Yum, J.H.; Ballif, C. Organometallic halide perovskites: Sharp optical absorption edge and its relation to photovoltaic performance. J. Phys. Chem. Lett. 2004, 5, 1035-1039. [CrossRef]

38. Wehrenfennig, C.; Liu, M.; Snaith, H.J.; Johnston, M.B.; Herz, L.M. Homogeneous, Emission Line Broadening in the Organo Lead Halide Perovskite $\mathrm{CH}_{3} \mathrm{NH}_{3} \mathrm{PbI}_{3}-x \mathrm{Clx}$. J. Phys. Chem. Lett. 2014, 5, 1300. [CrossRef]

39. Ha, S.-T.; Shen, C.; Zhang, J.; Xiong, Q. Laser cooling of organic-inorganic lead halideperovskites. Nat. Photonics 2016, 10, 243. [CrossRef]

40. Ashurov, N.; Oksengendler, B.L.; Maksimov, S.; Rashiodva, S.; Ishteev, A.R.; Saranin, D.S.; Burmistrov, I.N.; Kuznetsov, D.V.; Zakhisov, A.A. Current state and perspectives for organo-halide perovskite solar cells. Part Crystal structures and thin film formation, morphology, processing, degradation, stability improvement by carbon nanotubes. A review. Mod. Electron. Mater. 2017, 3, 1-25. [CrossRef]

41. Proctor, C.M.; Nguyen, T.-Q. Effect of leakage current and shunt resistance on the light intensity dependence of organic solar cells. Appl. Phys. Lett. 2015, 106, 083301. [CrossRef]

42. Koster, L.J.A.; Mihailetchi, V.D.; Ramaker, R.; Blom, P.W.M. Light intensity dependence of open-circuit voltage of polymer:fullerene solar cells. Appl. Phys. Lett. 2005, 86, 123509. [CrossRef]

43. Mauer, R.; Howard, I.A.; Laquai, F. Effect of nongeminate recombination on fifill factor in polythio-phene/methanofullerene organic solar cells. J. Phys. Chem. Lett. 2010, 1, 3500-3505. [CrossRef]

44. Pascoe, A.R.; Duffy, N.W.; Scully, A.D.; Huang, F.; Cheng, Y.-B. Insights into Planar $\mathrm{CH}_{3} \mathrm{NH}_{3} \mathrm{PbI}_{3}$ Perovskite Solar Cells Using Impedance Spectroscopy. J. Phys. Chem. C 2015, 119, 4444-4453. [CrossRef]

45. Zhu, L.; Chen, C.; Li, F.; Shen, Z.; Weng, Y.; Huang, Q.; Wang, M. Enhancing the efficiency and stability of perovskite solar cells by incorporating $\mathrm{CdS}$ and $\mathrm{Cd}\left(\mathrm{SCN}_{2} \mathrm{H}_{4}\right) 2 \mathrm{Cl}_{2}$ into the $\mathrm{CH}_{3} \mathrm{NH}_{3} \mathrm{PbI}_{3}$ active layer. J. Mater. Chem. A 2019, 7, 1124-1137. [CrossRef]

46. Pham, N.D.; Tiong, V.T.; Chen, P.; Wang, L.; Wilson, G.J.; Bell, J.; Wang, H. Enhanced perovskite electronic properties via a modified lead(ii) chloride Lewis acid-base adduct and their effect in high-efficiency perovskite solar cells. J. Mater. Chem. A 2017, 5, 5195-5203. [CrossRef]

47. Lee, J.; Baik, $\mathrm{S}$. Enhanced crystallinity of $\mathrm{CH}_{3} \mathrm{NH}_{3} \mathrm{PbI}_{3}$ by the precoordination of PbI2-DMSO powders for highly re-producible and efficient planar heterojunction perovskite solar cells. RSC Adv. 2018, 8, 1005-1013. [CrossRef]

48. Zhu, Z.; Bai, Y.; Lee, H.K.H.; Mu, C.; Zhang, T.; Zhang, L.; Wang, J.; Yan, H.; So, S.K.; Yang, S. Polyfluorene Derivatives are High-Performance Organic Hole-Transporting Materials for Inorganic-Organic Hybrid Perovskite Solar Cells. Adv. Funct. Mater. 2014, 24, 7357-7365. [CrossRef]

49. Leijtens, T.; Stranks, S.D.; Eperon, G.E.; Lindblad, R.; Johansson, E.M.J.; McPherson, I.J.; Rensmo, H.; Ball, J.M.; Lee, M.M.; Snaith, H.J. Electronic Properties of Meso-Superstructured and Planar Organometal Halide Perovskite Films: Charge Trapping, Photodoping, and Carrier Mobility. ACS Nano 2014, 8, 7147-7155. [CrossRef]

50. Wehrenfennig, C.; Liu, M.; Snaith, H.J.; Johnston, M.B.; Herz, L.M. Charge Carrier Dynamics in Va-pour-Deposited Films of the Organolead Halide Perovskite $\mathrm{CH}_{3} \mathrm{NH}_{3} \mathrm{PbI}_{3}-x \mathrm{Clx}$. Energy Environ. Sci. 2014, 7, 2269-2275. [CrossRef]

51. Zarazua, I.; Han, G.; Boix, P.P.; Mhaisalkar, S.; Fabregat-Santiago, F.; Mora-Seró, I.; Bisquert, J.; Garcia-Belmonte, G. Surface Recombination and Collection Efficiency in Perovskite Solar Cells from Impedance Analysis. J. Phys. Chem. Lett. 2016, 7, 5105-5113. [CrossRef]

52. Xing, G.; Mathews, N.; Sun, S.; Lim, S.S.; Lam, Y.M.; Grätzel, M.; Mhaisalkar, S.; Sum, T.C. Long-Range Balanced Electron- and Hole-Transport Lengths in Organic-Inorganic $\mathrm{CH}_{3} \mathrm{NH}_{3} \mathrm{PbI}$. Science 2013, 342, 344-347. [CrossRef] [PubMed]

53. Younts, R.; Duan, H.-S.; Gautam, B.; Saparov, B.; Liu, J.; Mongin, C.; Castellano, F.N.; Mitzi, D.B.; Gundogdu, K. Efficient Generation of Long-Lived Triplet Excitons in 2D Hybrid Perovskite. Adv. Mater. 2017, 29, 1604278. [CrossRef]

54. Gadisa, A. Studies of Charge Transport and Energy Level in Solar Cells Based on Polymer/Fullerene Bulk Heterojunction. Ph.D. Thesis, Linköping University, Linköping, Sweden, 2006.

55. Van Duren, J.K.J.; Yang, X.; Loose, J.; Bulle-Lieuwma, C.W.T.; Sieval, A.B.; Hummelen, J.C.; Lanssen, A.J. Re-lating the morphology of poly(p-phenylene vinylene)/methanofullerene blends to solar cell performance. Adv. Funct. Mater. 2004, 14, 425-434. [CrossRef]

56. Gartstein, Y.; Conwell, E. Field-dependent thermal injection into a disordered molecular insulator. Chem. Phys. Lett. 1996, 255, 93-98. [CrossRef]

57. Deibel. Available online: https://blog.disorderedmatter.eu/2016/05/14/the-diode-ideality-factor-inorganic-solar-cellsrecombination (accessed on 18 December 2017).

58. Rau, U. Tunneling-enhanced recombination in $\mathrm{Cu}(\mathrm{In}, \mathrm{Ga}) \mathrm{Se}_{2}$ heterojunction solar cells. Appl. Phys. Lett. 1999, 74, 111-113. [CrossRef]

59. Eron, M.; Rothwarf, A. Status of CuISe 2 of Solar Cells. J. Appl. Phys. 1985, 57, 2275-2279. [CrossRef] 
60. Verschraegen, J.; Burgelman, M.; Penndorf, J. Temperature dependence of the diode ideality factor in CuInS2-on-Cu-tape solar cells. Thin Solid Films 2005, 480-481, 307-311. [CrossRef]

61. Kinoshita, T.; Nonomura, K.; Jeon, N.J.; Giordano, F.; Abate, A.; Uchida, S.; Kubo, T.; Seok, S.; Nazeeruddin, M.K.; Hag-feldt, A.; et al. Spectral splitting photovoltaics using perovskite and wideband dye-sensitized solar cells. Nat. Commun. 2015, 6, 8834. [CrossRef]

62. Mesquita, I.; Andrade, L.; Mendes, A. Perovskite solar cells: Materials, configurations and stability. Renew. Sustain. Energy Rev. 2018, 82, 2471-2489. [CrossRef]

63. Khadka, D.B.; Shirai, Y.; Yanagida, M.; Miyano, K. Degradation of encapsulated perovskite solar cells driven by deep trap states and interfacial deterioration. J. Mater. Chem. C 2018, 6, 162-170. [CrossRef] 